\title{
Influence Factors of Drying Speed on Water-based Self-drying I Fast-drying Foundry Coatings
}

\author{
Shengshan FENG ${ }^{1, a}$, Chunyi ZHAN ${ }^{1, b}$, Shuzhong XIE $^{2}$, Chunjing LIU $^{2}$, Jiahao \\ LIANG $^{2}$, Yunhua GAO ${ }^{2}$ \\ ${ }^{1}$ School of mechanical and Electrical Engineering, Guangdong Institute of Science and Technology, \\ Zhuhai, 519090, China
}

${ }^{2}$ Zhuhai Doumen Fulian Molding Materials Industry Co.Ltd, Zhuhai, 519180, China

aemail: fss8172@126.com, bemail:richardzhan@hotmail.com

Keywords: Water-based; Self-drying; Coating; Drying

\begin{abstract}
Factors affected drying speed of energy saving and environment friendly water-based self-drying / fast-drying foundry coatings and its regularity changing were analyzed. The results show that the self-drying speed of coating is improved significantly with the decrease of humidity and the increase of temperature, the coating is able to naturally dry in about 2 hours under the condition of $25^{\circ} \mathrm{C}$ and $80 \% \mathrm{RH}$, the self-drying speed of coating increases in an approximately linear manner with the decreasing of its thickness, the hot air quick drying time of the water-based self-drying / fast-drying coating is $3.5 \sim 7.0 \mathrm{~min}$ when the thickness of coatings is $0.3 \sim 0.8 \mathrm{~mm}$ and the hot air temperature is $80^{\circ} \mathrm{C} \pm 5^{\circ} \mathrm{C}$.
\end{abstract}

\section{Introduction}

Water-based self-drying / fast-drying foundry coatings has the advantages of safe, convenient transportation, lower cost, no-contamination, good suspension property and brushability, fast air drying speed etc. It overcomes the problems of alcohol-based coating such as easy inflammability, easy explosion, poisonousness, suspension stability, serious brush marks when brushing and the problems of common water-based coating such as need for drying, difficult to dry, easy hygroscopicity of coating and so on[1-6]. From the point of view of saving energy and reducing consumption, improving working conditions, improving production safety and surface quality of castings and so on, water-based self-drying / fast-drying coatings is the development direction of sand casting coating.

We developed a new water-based self-drying / fast-drying foundry coating, using the natural refractory material without calcination or electric melting as base material and self-made normal temperative cured modified polymer emulsion organic adhesive as main self-drying / low temperature fast drying adhesive at room temperature, at the same time, using the fast-drying silicate adhesive as main high temperature adhesive. It has good brushability and low permeability conditions under the condition of high viscosity and solid content (volatile content), can be fast drying at low drying temperature in a short time, or be fast surface drying using torch, gas, oxygen acetylene gas or hot blast short time rapid surface drying, that can be fast natural drying under the condition of high ambient temperature, low humidity and good ventilation conditions without worsening the sand strength. The dried coating has good moisture resistant absorption ability, which provides good conditions for foundry enterprises to save energy consumption, improve environmental conditions and the quality of castings.

\section{Test instruments and methods}

\section{Self-drying time $(h)$}

Self-drying time of coatings is tested using QGZ type paint film drying time tester under the condition of $25^{\circ} \mathrm{C}$ and $80 \% \mathrm{RH}$, which characterizes drying speed of the coatings. The coatings is $0.5 \mathrm{~mm}$ thick and on the planar basement of resin sand. 


\section{Wear loss}

The wear loss of coatings is the characterization value of wear resistance of coatings and it characterizes the cohesive strength of coatings indirectly.

The wear loss of coatings is tested using JM-IV type paint film abrasion tester. The sample is a resin sand plate with a diameter of $105 \mathrm{~mm}$ and thickness of $10 \mathrm{~mm}$. The coatings is thoroughly dried and its thickness is $1.0 \sim 1.5 \mathrm{~mm}$. The test condition is $750 \mathrm{~g}$ load and friction with grinding wheel 60r. The quality difference of coated circular plate before and after the test is the wear loss of coatings.

We use the "relative strength" to characterize when using the wear loss of coatings to compare the difference and change of the strength of coatings. Suppose the relative strength of reference sample is one and the wear loss of it is A0, while the wear loss of others is Ax, then the relative strength of some sample is $\mathrm{Rx}=\mathrm{A} 0 / \mathrm{Ax}$.

\section{Coating thickness}

The striking thickness of coatings is controlled by adjustable paint film preparation device.

\section{Test results and analysis}

\section{Self-drying curing characteristics of coatings}

Foundry coating should not only have certain strength at room temperature, but also good strength at high temperature. According to the demand, we develop a curable modified polymer emulsion at room temperature as main self-drying / low temperature quick drying adhesive, at the same time, also using a fast-drying type inorganic binder as main high temperature adhesive, with the corresponding latent type hardener.

Self-made normal temperative cured modified polymer emulsion is synthesized by monomer, water, water soluble initiator and water soluble emulsifier etc. The curing mechanism of the emulsion adhesive is the interaction of the following two kinds of reaction: one is the physical hardening caused by water evaporation loss, two is the chemical hardening after the system changing acidic. The emulsion becomes a weak acid after the synthesis is finished. In order to improve storage stability of the emulsion, a volatile alkaline liquid is needed to change it into alkaline, because it is not generally cured under alkaline conditions (PH8). After the coating application of thin coating, the moisture and alkaline liquid in the emulsion evaporate at the same time, the system changes into acid, the curing reaction of emulsion will happen under the influence of cross linking agent. The volatile alkaline liquid is latent type hardener.

The fast-drying inorganic binder used in this coating contains water insoluble organic fiber, that plays a role in the drying process of binder as capillaries and speeds up the internal moisture evaporation.

The compatibility of normal temperative cured modified polymer emulsion and fast-drying inorganic binder is very good. When used together, the polymer also has physical binding effect on the inorganic binder particles, which can decrease the critical concentration of gelation of inorganic binder thus achieving the concentration of gelation fastly, shortening the drying time further.

As shown in figure 1, how strength of the new water-based self-drying coatings grows and changes over time. 


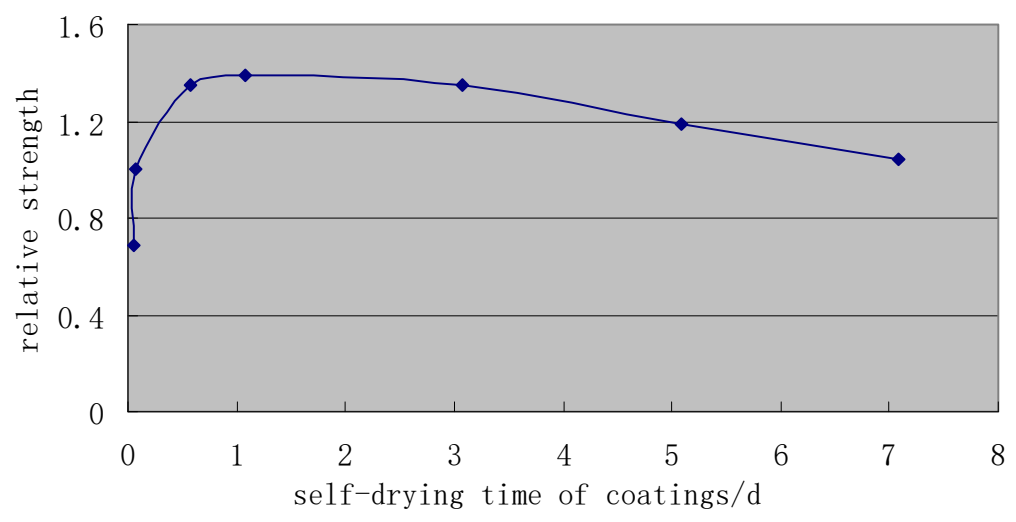

Fig.1. The self-drying curing characteristics of water-based self-drying coatings

The process can be divided into the following four stages: initial dehydration-transformation stage (about $10 \mathrm{~min} \sim 30 \mathrm{~min}$ )、 middle physical-chemical common curing stage(about 30min $\sim 3 \mathrm{~h}$ )、 later chemical curing stage (about $3 \mathrm{~h} \sim 1 \mathrm{~d}$ ) and storage moisture absorption stage (about $1 \mathrm{~d} \sim 7 \mathrm{~d}$ ) [1].

\section{Influence on the coatings' drying speed of environmental conditions}

Owing to the evaporative loss of coatings' moisture, physical hardening caused by the close packing of polymer binder is one of the curing ways of the water-based self-drying coatings. So the temperature and humidity of coatings' environment are important conditions that naturally influence the self-drying curing speed or self-drying time of coatings.

Water evaporation speed of the coatings' surface can be expressed as the following formula:

$$
\mathrm{v}=\mathrm{k}\left(\mathrm{P}_{\mathrm{w}}-\mathrm{P}_{\mathrm{a}}\right)
$$

In the type: $v$ is evaporation speed; $k$ is mass transfer coefficient; $P_{w}$ is the partial pressure of water vapor by water evaporation of coatings' surface; $P_{a}$ is the partial pressure of environment.

Since the partial pressure of environment $\mathrm{P}_{\mathrm{a}}$ increases in high humidity conditions, and the partial pressure of coatings' surface is related to the temperature, so when the temperature is basically constant, the evaporation speed of coatings' surface decreases as the humidity increases. And thus the self-drying time of coatings will be extended and the self-drying speed be reduced.

Figure 2 shows the relationship between the self-drying time of coatings and the wear loss and environmental humidity under laboratory conditions (environmental temperature is $25^{\circ} \mathrm{C}$ ). The experimental data shows:

(1) When the environmental temperature is basically constant, the self-drying time of coatings is significantly prolonged and the self-drying speed decreases with the increase of environmental humidity;

(2) After the coatings are fully dried, the strength (or wear loss) has nothing to do with the environmental humidity.

The air flow velocity can be increased to obtain a higher water evaporation speed.

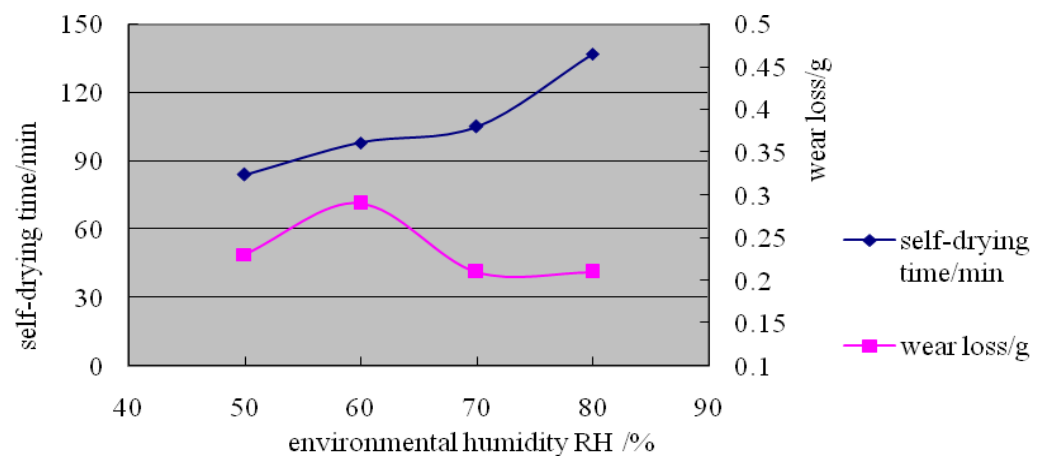

Fig.2. The effect of environmental humidity on self-drying time and wear loss of the coating 


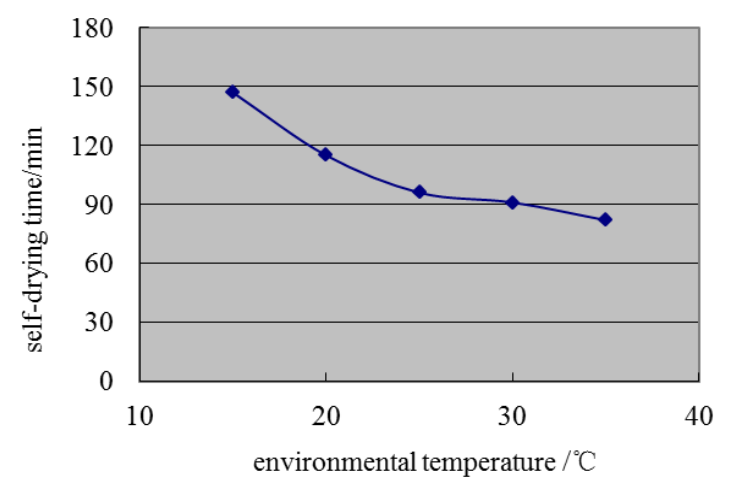

Fig.3. The effect of environment temperature on self-drying time of the coating

Figure 3 shows the relationship between the self-drying time of coatings and environmental temperature under laboratory conditions (environmental humidity is $75 \%$ ). The experimental data shows that when the environmental humidity is basically constant, the self-drying time of coatings is sharply cut and the curing speed is significantly increased with the increase of environmental temperature.

\section{Effect of coatings' thickness on self-drying time}

Figure 4 shows the experimental results of the effect of water-based self-drying coatings' thickness on self-drying rate of coatings( the experimental conditions: temperature $26-27^{\circ} \mathrm{C}$ and relative humidity $40-46 \%$ ). It can be seen from fig.4 that the self-drying time of water-based self-drying coating basically is approximate linearly prolonged with the increase of coatings' thickness, the coatings' self-drying speed basically is approximate linearly decreased with the increase of coatings' thickness as well.

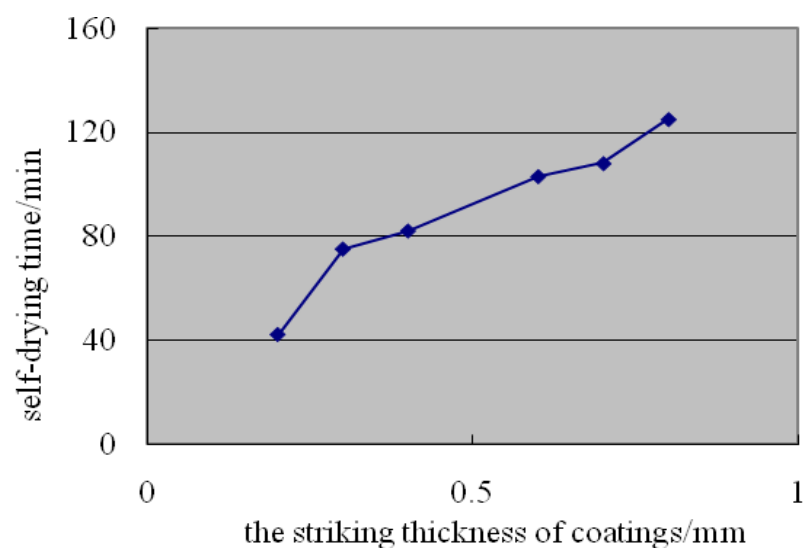

Fig.4. The effect of coatings' thickness on self-drying time of the coatings

\section{Hot air drying speed of coatings}

In order to eliminate the adverse effect of high air-humidity on natural drying and curing speed of new water-based coatings, the air temperature needs to be increased, while increasing air flow speed, namely using hot air to accelerate the drying speed of coatings.

Nowadays widely used molding and core making process are mainly the two that are resin sand and water glass sand. When the heating temperature of resin sand is higher than $150^{\circ} \mathrm{C}$, its strength begins to decrease. And when the heating temperature of water glass sand is higher than $250^{\circ} \mathrm{C}$, its strength also begins to decrease. Therefore, if the new water-based coating uses hot air for fast curing, the hot air temperature should be less than $150^{\circ} \mathrm{C}$. Moreover, considered from the perspective of energy saving, the hot air temperature should be as low as possible, and be controlled below $100^{\circ} \mathrm{C}$. Considering the test conditions of similar products in the world, the test conditions of fast-drying speed of the new water-based coatings is determined to be $80^{\circ} \mathrm{C}$ of hot air temperature.

Table 1 lists out the experimental results of the effect of water-based fast-drying coatings' thickness on hot air fast-drying speed of coatings. 
Table 1. the effect of the coatings' thickness on hot air fast-drying time of coatings

\begin{tabular}{cc}
\hline striking thickness of coatings $/ \mathrm{mm}$ & hot air fast-drying time $/ \mathrm{min}$ \\
\hline 0.3 & $3.5 \sim 4.0$ \\
0.5 & $4.0 \sim 4.5$ \\
0.6 & $5.0 \sim 5.5$ \\
0.7 & $5.5 \sim 6.0$ \\
0.8 & $6.5 \sim 7.0$ \\
\hline
\end{tabular}

As can be seen from the table, the coatings' hot air fast-drying time of water-based fast-drying extends with the increase of coatings' thickness. When the striking thickness of coatings is $0.3 \sim 0.8 \mathrm{~mm}$ and the hot air temperature is $80^{\circ} \mathrm{C} \pm 5^{\circ} \mathrm{C}$, the hot air fast-drying time of four water-based fast-drying coatings are all between $3.5 \sim 7.0 \mathrm{~min}$. The hot air fast- drying speed is faster than 9022 FD type fast-drying water-based coating of one well-known international company, which is less than $10 \mathrm{~min}$.

Accelerating wind speed can make air layer on the evaporation interface of coatings thinner, strengthen the heat transfer and outward diffusion of steam, thus improving the drying speed of coatings.

\section{Conclusion}

The curing mechanism of new water-based self-drying / fast-drying foundry coating is the following two kinds of interactions: one is the physical hardening caused by water evaporation loss, and the other is the chemical hardening after the system changing acidic. The self-drying curing process can be divided into the following three stages: initial dehydration-transformation stage 、 middle physical-chemical common curing stage and later chemical curing stage.

The self-drying speed of water-based self-drying / fast-drying coatings is significantly increased with the decrease of environmental humidity and the increase of environmental temperature. The coating will basically realize natural drying in about 2 hours under the condition of $25^{\circ} \mathrm{C}$ and $80 \%$ RH. The self-drying speed reaches international advanced level of the same type of products.

The self-drying speed of water-based self-drying / fast-drying coatings increases in an approximately linear manner with the decrease of its thickness.

In order to eliminate the adverse effect of high air-humidity on natural drying and curing speed of new water-based coatings, the air temperature needs to be increased, while increasing air flow speed, namely using hot air to accelerate the drying speed of coatings. When the thickness of coatings is $0.3 \sim 0.8 \mathrm{~mm}$ and the hot air temperature is $80^{\circ} \mathrm{C} \pm 5^{\circ} \mathrm{C}$, the hot air fast-drying time of water-based fast-drying coatings are all between $3.5 \sim 7.0 \mathrm{~min}$. The hot air fast- drying speed is faster than 9022 FD type fast-drying water-based coating of one well-known international company, which is less than $10 \mathrm{~min}$.

\section{Acknowledgement}

In this paper, the research was sponsored by the Science and Technology Research and High-tech Industrialization Projects of Zhuhai City, Guangdong Province, China (Project No. 2011B020102013).

\section{References}

[1] Feng Sheng-shan, Xie Shu-zhong, Liu Chun-jing, ET al. Technological properties of water-based self-drying / fast-drying foundry coating[C]. China Foundry week Symposium. 2014.

[2] Liu Sheng-yin, Sun Xing-hua, Jin Xiao-chun, ET al. Development the Water-based coating for 
cold box process[C]. China Foundry week Symposium. 2008.

[3] Liu Cheng-yao. Property and Application on PVA Water-Based Air-Dried Coating [J]. Foundry, 1990(3) 23-27.

[4] Wei Zhao-lian, Cao Li-hong. Study on Phosphate No-bake Moldcoating[J]. Journal of Wuhan Institute of Technology, 1992(4) 40-46.

[5] Wei Zhao-lian, Cao Li-hong. The High Temperature Properties of Phosphate No-bake Moldcoatings [J]. Special Casting \& Nonferrous Alloys, 1994(5) 17-20.

[6] Hu You-fu. Production Test of JZ-1 Water-based Fast-drying Coatings[J]. Auto Mobile Science \& Technology, 1993(3) 23-28. 